OPEN ACCESS

Edited by

Xinxiang $L i$,

Fudan University, China

Reviewed by:

Zubing Mei,

Shanghai University of Traditional

Chinese Medicine, China

Giacomo Bregni,

Jules Bordet Institute, Belgium

${ }^{*}$ Correspondence:

Xuehu Xu

xxh@gzhmu.edu.cn

Yanhong Deng

dengyanh@mail.sysu.edu.cn

${ }^{\dagger}$ These authors have contributed equally to this work

Specialty section:

This article was submitted to

Gastrointestinal Cancers,

a section of the journal

Frontiers in Oncology

Received: 02 July 2020 Accepted: 28 October 2020 Published: 04 December 2020

Citation:

Hu H, Wu Z, Wang C, Huang Y,

Zhang J, Cai Y, Xie X, Li J, Shen C,

Li W, Ling J, Xu $X$ and Deng $Y$ (2020)

Duration of FOLFOX Adjuvant

Chemotherapy in High-Risk Stage II

and Stage III Colon Cancer With

Deficient Mismatch Repair.

Front. Oncol. 10:579478.

doi: 10.3389/fonc.2020.579478

\section{Duration of FOLFOX Adjuvant Chemotherapy in High-Risk Stage II and Stage III Colon Cancer With Deficient Mismatch Repair}

\author{
Huabin $\mathrm{Hu}^{1,2,3 \dagger}$, Zehua $\mathrm{Wu}^{2,3 \dagger}$, Chao Wang ${ }^{3,4 \dagger}$, Yan Huang ${ }^{3,4}$, Jianwei Zhang ${ }^{2,3}$, \\ Yue Cai ${ }^{2,3}$, Xiaoyu Xie ${ }^{2,3}$, Jianxia $L_{i}^{2,3}$, Cailu Shen ${ }^{2,3}$, Weiwei $L^{2,3}$, Jiayu Ling ${ }^{2,3}$, \\ Xuehu $\mathrm{Xu}^{1 *}$ and Yanhong Deng ${ }^{2,3^{*}}$ \\ ${ }^{1}$ Department of Gastrointestinal Surgery, The Third Affiliated Hospital of Guangzhou Medical University, Guangzhou, China, \\ 2 Department of Medical Oncology, The Sixth Affiliated Hospital of Sun Yat-sen University, Guangzhou, China, ${ }^{3}$ Guangdong \\ Institute of Gastroenterology, Guangdong Provincial Key Laboratory of Colorectal and Pelvic Floor Diseases, Guangzhou, China, \\ ${ }^{4}$ Department of Pathology, The Sixth Affiliated Hospital of Sun Yat-sen University, Guangzhou, China
}

Background: We evaluated the impact of 3 months of mFOLFOX6 adjuvant chemotherapy or surgery alone in comparison with 6 months of mFOLFOX6 on diseasefree survival (DFS) in deficient mismatch repair (dMMR) colon cancer (CC) patients.

Methods: This retrospective study identified a cohort of patients with high-risk stage II and III dMMR CC who underwent curative surgery between May 2011 and July 2019. DFS was compared using the Kaplan-Meier survival methods and Cox proportional hazards models. Propensity-score matching was performed to reduce imbalance in baseline characteristics.

Results: A total of 242 dMMR CC patients were identified; 66 patients received 6 months of mFOLFOX6, 87 patients received 3 months of mFOLFOX6, and 89 patients were treated with surgery alone. The 3-year DFS rate was $72.8 \%$ in 3-month therapy group and $86.1 \%$ in 6-month therapy group, with a hazard ratio $(\mathrm{HR})$ of $2.78(95 \mathrm{Cl} \%, 1.18$ to 6.47 ; $\mathrm{P}=0.019)$. The difference in DFS between surgery alone group and 6-month therapy group was also observed but was nonsignificant $(\mathrm{HR}=2.30,95 \% \mathrm{Cl}, 0.99$ to 5.38; $\mathrm{P}=0.054)$. The benefit of 6-month therapy in DFS compared with 3-month therapy group was pronounced for patients with stage III $(\mathrm{HR}=2.81,95 \% \mathrm{Cl}, 1.03$ to 7.67 ; $\mathrm{P}=0.044)$ but not for high-risk stage II patients. Propensity score matched analysis confirmed a DFS benefit in the 6-month therapy group.

Conclusion: This study suggested that a 6-month duration of mFOLFOX6 adjuvant chemotherapy in dMMR CC patients may be associated with improved DFS compared with 3-month therapy, particularly in patients with stage III. The observational nature of the study implies caution should be taken in the interpretation of these results.

Keywords: colon cancer, adjuvant chemotherapy, deficient mismatch repair, microsatellite instability, duration of therapy 


\section{INTRODUCTION}

As the fourth most commonly seen cancer worldwide, colon cancer (CC) leads to 550,000 deaths each year (1). On the basis of positive findings from three phase- 3 trials, 6 months of FOLFOX (fluorouracil, leucovorin, and oxaliplatin) or CAPOX (capecitabine and oxaliplatin) became the standard adjuvant therapy for patients with stage III CC (2-6). Given the neurotoxicity of oxaliplatin accumulated amid therapy that might affect patients' daily-life activities, shorter duration of adjuvant therapy was afforded to reduce adverse effects (7). However, the non-inferiority of 3 months of adjuvant therapy with either FOLFOX or CAPOX versus 6 months was not confirmed for overall CC patients in an IDEA collaboration study. Furthermore, among the patients who received FOLFOX, results of those who received 6 months of adjuvant therapy were superior to those receiving 3 months $(8,9)$.

Colorectal cancer is a biologically heterogeneous disease that develops via 2 well described pathways of colorectal carcinogenesis, including chromosomal instability and, less commonly, microsatellite instability (MSI). MSI is a consequence of a deficient mismatch repair (dMMR) system that results in error accumulation within microsatellite region, and it occurs in approximately $15 \%$ of all colorectal cancers (10). Several studies have shown that dMMR non-metastatic CC patients were associated with a more favorable stage-adjusted prognosis compared to patients with proficient mismatch repair (pMMR) (11-14). Whether a shorter duration of adjuvant therapy for patients with dMMR would lead to any decrease in efficacy is still unclear. Thus, we evaluated the impact of 3 months of mFOLFOX6 adjuvant chemotherapy or surgery alone in comparison with 6 months of mFOLFOX6 on disease-free survival (DFS) in high-risk stage II and stage III patients with dMMR.

\section{METHOD}

\section{Study Population}

This retrospective study included all consecutive patients with histologically confirmed high-risk stage II or III CC and determined dMMR tumors who received radical surgical resection from May 2011 to July 2019 at The Sixth Affiliated Hospital of Sun Yat-Sen University. Patients with rectal cancer, incomplete curative resection (R1 or R2 resection), stage I and stage II without any highrisk factors, or adjuvant chemotherapy with fluoropyrimidine alone, CAPOX regimen (capecitabine and oxaliplatin), or duration less than 3 months were excluded. High-risk stage II CC was defined by pathologic stage T4, vascular invasion, lymphatic infiltration, perineural invasion, initial bowel obstruction, tumor perforation, or fewer than 12 excised lymph nodes (15). This study was approved by the Institutional Review Boards of The Sixth Affiliated Hospital of Sun Yat-Sen University.

\section{IHC Analysis of MMR Protein Expression}

Formalin-fixed, paraffin-embedded tumors were stained for MLH1, MSH2, MSH6, and PMS2 proteins. Mismatch repair protein loss is defined as the absence of nuclear staining in neoplastic cells but positive nuclear staining in lymphocytes and normal adjacent colonic epithelium (16). Primary monoclonal antibodies against MLH1 (clone M1, Ventana, prediluted), MSH2 (clone G219-1129, Ventana, prediluted), MSH6 (clone 44, Ventana, prediluted), and PMS2 (clone EPR3947, Ventana, prediluted) were applied.

\section{MSI Testing}

DNA was extracted from formalin-fixed paraffin-embedded (FFPE) tumor tissues. Comparative analysis of normal colon and tumor DNA using the five consensus monomorphic mononucleotide markers (BAT-25, BAT-26, NR-21, NR-24, NR-27) obtained through polymerase chain reaction (PCR)-based assay was adopted to assess the microsatellite instability (MSI). Specimens with at least 2 unstable markers were scored as highly unstable, while those with fewer than 2 unstable markers were stable (17).

\section{MMR Status Determination}

MMR status was tested though the analysis of MMR protein expression by immunohistochemistry (IHC), and to be further confirmed by PCR-based MSI testing when the IHC result was undetermined. Deficient MMR phenotype tumors were defined as exhibiting the loss of expression of 1 or more MMR protein by IHC or high-level tumor DNA MSI by PCR. Tumors with discordant results between MMR protein expression and DNA MSI testing were not included in the study.

\section{Gene Mutation Detection}

Under adequate quality-control procedures, mutation analysis was performed at the Molecular Diagnostic Laboratory of the Sixth Affiliated Hospital of Sun Yat-sen University. Genomic DNA was extracted from FFPE samples of surgery with an EZgene Tissue gDNA miniprep kit (Cat no: GD2211, Biomiga, China). KRAS (exons 2, 3, 4), NRAS (exons 2, 3, 4), BRAF (exon 15, V600E mutations), and PIK3CA (exon 9 and 20) were evaluated by bidirectional sequencing using ABI Prism 3500 DX genetic Analyzer (Applied Biosystems, Foster City, CA).

\section{Treatment and follow-Up}

All patients in this study underwent curative surgical resection, followed by either adjuvant chemotherapy with mFOLFOX6 regimen (oxaliplatin $85 \mathrm{mg} / \mathrm{m}^{2}$, leucovorin $400 \mathrm{mg} / \mathrm{m}^{2}$, fluorouracil $400 \mathrm{mg} / \mathrm{m}^{2}$, and fluorouracil $2400 \mathrm{mg} / \mathrm{m}^{2}$ by 48 hours continuous intravenous infusion) for 3 to 6 months or observation only. Follow-up routines consisted of physical examination, serum carcinoembryonic antigen (CEA) assay, and computed tomography scan (chest/ abdominal/pelvic) every 3 to 6 months in the first 3 years and every 6 months in the following 2 years. The data were updated in December 2019.

\section{Propensity Score Matching}

We performed propensity score matching to reduce imbalances in baseline characteristics between patients who received 3 months of mFOLFOX6 or surgery alone and those who received 6 months of mFOLFOX6. A multivariable logistic regression model was constructed to generate propensity scores. We selected covariates for inclusion in the propensity model based on factors presumed to be associated with the patient's survival outcomes. The following baseline data were included in the model: age at diagnosis, 
pathologic $\mathrm{T}$ stage, pathologic $\mathrm{N}$ stage, initial bowel obstruction, vascular invasion and/or lymphatic infiltration, and perineural invasion. Patients who received 3 months of mFOLFOX6 and surgery alone were matched to those who received 6 months of mFOLFOX6 in a 1:1 ratio respectively, according to a greedy nearest-neighbor matching algorithm with no replacement. A caliper width equal to 0.2 of the standard deviation was utilized as the logit of the propensity score. We compared baseline characteristics between the propensity score-matched group using standardized differences. A standardized difference of less than 0.1 can be regarded as negligible imbalance between groups (18).

\section{Statistical Analysis}

Categorical variables were compared by dint of the Chi-square test or Fisher's exact test. DFS was defined as the time from surgery to the first event of local or metastatic recurrence, second primary cancer, or death from any cause. DFS curves were estimated via the Kaplan-Meier method and were compared by means of COX proportional hazards regression model with hazard ratios (HR), 95\% confidence intervals (CI), and $\mathrm{P}$ values for candidate prognostic factors. Variables with $\mathrm{P}$ values of 0.05 or less in univariate analysis or clinically relevant were eligible for the multivariate analyses. Two-sided $\mathrm{P}$ values of less than 0.05 were designated as statistically significant. Apart from propensity score matching, which was implemented in $\mathrm{R}$, version 3.3.2 (R Foundation), using the package Matching, all statistical analyses were performed with the 22 version of SPSS software (SPSS Inc. Chicago, IL, USA).

\section{RESULTS}

\section{Patient Characteristics}

A total of 242 patients with high-risk stage II and III dMMR CC were identified. A complete consolidated standards of reporting trials (CONSORT) diagram depicting the selection process is outlined on Figure 1. The median age at diagnosis was 55 (range, 22 to 88 ), with $64.0 \%$ of the patients being men. All patients were tested for MMR status by IHC, and 38 cases were also confirmed by PCR-MSI testing. Among 242 patients, 139 (57.4\%) had lost MLH1 and PMS2 protein expression, 60 (24.8\%) with MSH2 and MSH6 expression, 14 (5.8\%) with MSH6 expression, and 29 (12.0\%) with PMS2 expression. Additionally, 176 patients had complete data for KRAS, NRAS, BRAF, and PI3KCA status.

Overall, 153 patients received adjuvant chemotherapy with mFOLOFX6 after surgery, which consisted of 6-month therapy $(27.3 \%, \mathrm{n}=66$; median cycles [range] $=12$ [9-12]) or 3-month therapy $(36.0 \%, \mathrm{n}=87$; median cycles [range] $=6$ [4-7]), and 89 patients $(36.7 \%)$ were treated with surgery alone. Baseline patients and tumor characteristics between treatment durations were presented in Table 1. Patients in the 6-month therapy group were more likely to be younger (< 65 years: $95.5 \%, 85.1 \%, 55.1 \%)$, with lower proportions of initial bowel obstruction $(27.3 \%, 33.3 \%, 47.2 \%)$, but more of them proceeded to stage III $(74.2 \%, 57.5 \%, 42.7 \%)$ with more positive lymph nodes examined (N1: 53.0\%, 42.5\%, 36.0\%; N2: $21.2 \%, 14.9 \%, 6.7 \%$ ) than those in the 3 -month therapy and surgery alone group.

\section{Association of Adjuvant Chemotherapy Duration and Disease-Free Survival}

For the overall cohort at the time of data cutoff, the median follow-up was 21.9 months. There were 17 DFS events in patients with high-risk stage II and 29 in stage III disease that led to a 3year DFS rate of $79.5 \%$ (95\%CI, $70.1 \%$ to $88.9 \%)$ and $73.4 \%$ (95\% CI, $64.2 \%$ to $82.6 \%$ ) respectively.

The 3-year DFS rate was $72.8 \%$ (95\%CI, $61.0 \%$ to $84.6 \%$ ) for patients who received 3 months of mFOLFOX6 therapy and $86.1 \%$ (95\%CI, $77.1 \%$ to $95.1 \%$ ) for patients who received 6 months of therapy, along with an estimated multivariate HR of 2.78 (95CI\%, 1.18 to $6.47 ; \mathrm{P}=0.019)$. For the patients treated with surgery alone, the 3 -year DFS rate was $72.4 \%$ (95\%CI, $60.8 \%$ to $84.0 \%$ ). The multivariate HR for DFS compared with 6-month therapy was 2.30 (95\%CI, 0.99 to 5.38; $\mathrm{P}=0.054$ ) (Figure 2, Table 2, and Supplementary Table S1).

Subgroup analysis demonstrated 3-year DFS rate for patients with stage III was $70.8 \%$ in the 3 -month therapy group and $86.2 \%$ in the 6-month therapy group $(\mathrm{HR}=2.81,95 \% \mathrm{CI}, 1.03$ to 7.67 ; $\mathrm{P}=0.044$ ). In high-risk stage II subgroup analysis, no significant effect of adjuvant chemotherapy duration on DFS was observed in the 3-month therapy group compared with the 6-month therapy group (Figure 3 and Supplementary Table S1).

\section{Disease-Free Survival After Propensity Score Matching}

At 1:1 propensity score matching, 51 patients who received 3month therapy and 35 patients treated with surgery alone were matched to the patients who received 6-month therapy respectively. As shown in Table 3, after propensity score matching, standardized differences for all included covariates among patients who received 6-month, 3-month therapy, and surgery alone were all less than 0.1 , indicating a well-balanced covariate distribution after matching.

After matching, a significant difference in DFS in favor of the 6month therapy group compared to the 3-month therapy group was observed. The 3-year DFS rate was $88.7 \%$ (95\%CI, $79.3 \%$ to $98.1 \%)$ and $68.7 \%$ (95\%CI, $52.2 \%$ to $85.2 \%)$ respectively, plus an estimated multivariate $\mathrm{HR}$ of 4.35 (95CI\%, 1.46 to $13.00 ; \mathrm{P}=0.008)$. In subgroup analysis, we identified a benefit on DFS of the 6-month adjuvant chemotherapy compared with the 3-month therapy for stage III patients (3-year DFS rate: $90.3 \%$ vs. $64.5 \%$; $\mathrm{HR}=5.88,95 \%$ CI, 1.44 to $24.04 ; \mathrm{P}=0.014$ ) (Figure 4). In contrast, there was still no significant difference in DFS between the two groups for high-risk stage II patients (Supplementary Table S2). Marginally significant difference in DFS between the 6-month therapy group and the surgery alone group was observed in the multivariable analysis $(\mathrm{HR}=3.02$, 95\%CI, 1.00 to $9.07 ; \mathrm{P}=0.049)$. The 3 -year DFS rate was $84.6 \%$ (95\%CI, $72.1 \%$ to $97.1 \%$ ) and $65.4 \%$ (95\%CI, $46.6 \%$ to $84.2 \%$ ) respectively (Figure 4 and Supplementary Table S3).

\section{DISCUSSION}

To our knowledge, this is the first study to explore the effect of the duration of mFOLFOX6 adjuvant chemotherapy on DFS in high-risk stage II and III dMMR CC patients, and it showed a statistically significant benefit in DFS in 6-month therapy group 


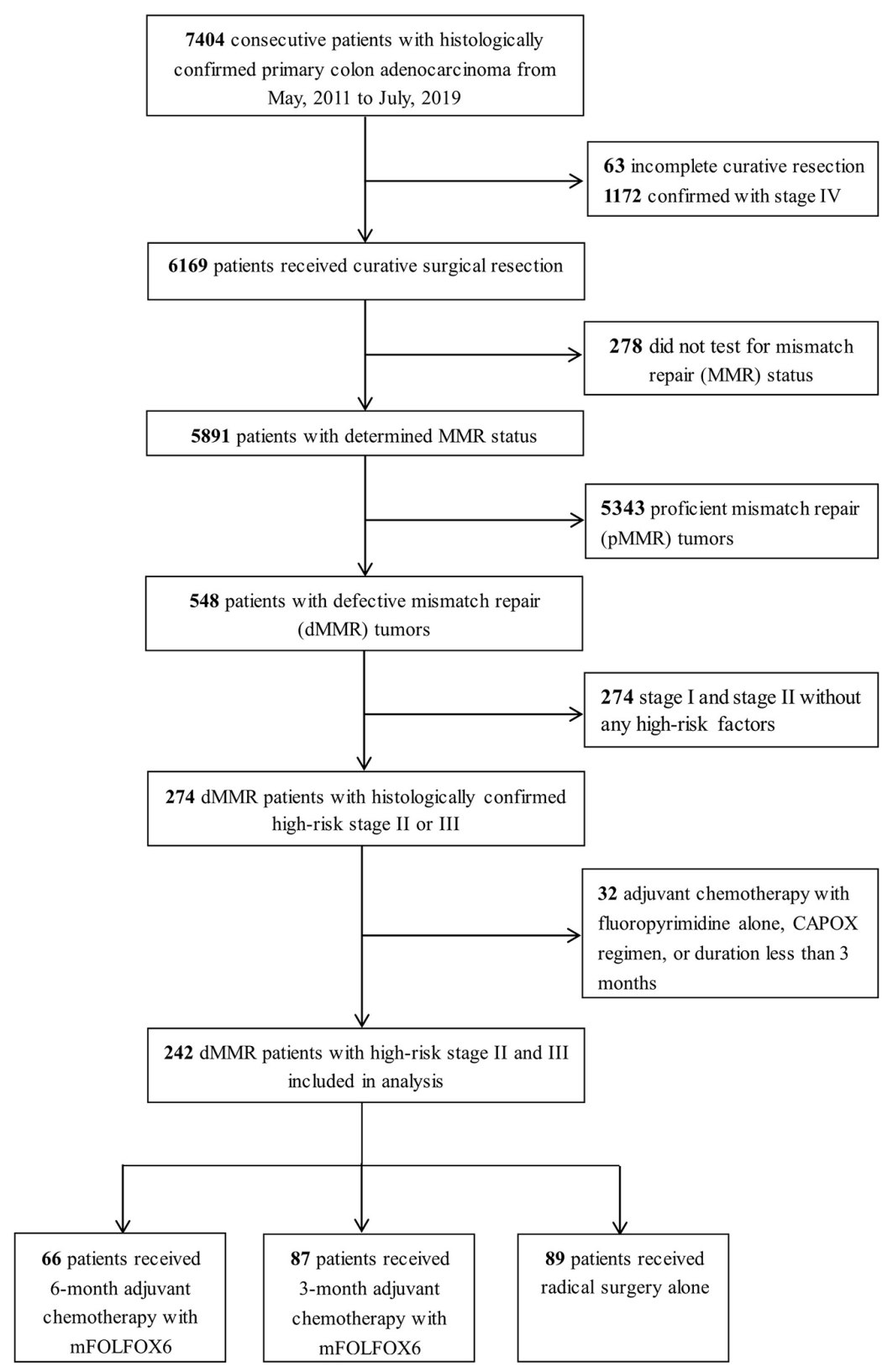

FIGURE 1 | Flow diagrams of the study population.

compared with the 3-month therapy group, particularly in patients with pathologic stage III.

Current guidelines recommend that all dMMR stage II CC patients, regardless of high-risk factors, should not receive 5-FUbased adjuvant therapy (11, 19-25). For dMMR stage III CC patients, adjuvant therapy with CAPOX or FOLFOX regimen is recommended, but the role of the MMR status as a predictive biomarker is still not completely clear $(23,24,26-28)$. IDEA collaboration and IDEA France study have failed to demonstrate the non-inferiority of 3-month FOLFOX to 6-month FOLFOX in stage III CC patients; however, these analyses did not perform a subgroup analysis of patients' dMMR status $(8,9)$. In keeping with the IDEA study, we observed that the 6-month duration of mFOLFOX6 adjuvant therapy may provide an additional DFS benefit compared with 3-month duration for dMMR stage III CC patients. In this subgroup of high-risk stage II CC patients, there were no significant differences in DFS among three groups, which implied that dMMR high-risk stage II CC patients did not significantly benefit from the FOLFOX adjuvant therapy however long the therapy duration was. The good prognosis of dMMR stage II CC patients, compared with stage III patients, might comparatively benefit less from the adjuvant therapy. 
TABLE 1 | Patients and tumor characteristics.

\begin{tabular}{|c|c|c|c|c|c|c|}
\hline Characteristics & $\begin{array}{l}\text { Missing } \\
\text { values }\end{array}$ & $\begin{array}{c}\text { All the popula- } \\
\text { tion, } n=242 \\
\text { No. }(\%)\end{array}$ & $\begin{array}{c}\text { 6-month therapy } \\
\text { group, } n=66 \\
\text { No. }(\%)\end{array}$ & $\begin{array}{c}\text { 3-month therapy } \\
\text { group, } n=87 \\
\text { No. }(\%)\end{array}$ & $\begin{array}{c}\text { Surgery alone } \\
\text { group, } \mathrm{n}=89 \\
\text { No. }(\%)\end{array}$ & $P$ \\
\hline \multicolumn{7}{|l|}{ Adjuvant therapy duration } \\
\hline Median (range), weeks & & - & $24(20-27)$ & $12(12-16)$ & 0 & \\
\hline \multicolumn{7}{|l|}{ Completion no. of cycles } \\
\hline Median (range) & & - & $12(9-12)$ & $6(4-7)$ & 0 & \\
\hline Age, years & & & & & & $<0.001$ \\
\hline$<65$ & & $186(76.9 \%)$ & $63(95.5 \%)$ & $74(85.1 \%)$ & 49 (55.1\%) & \\
\hline$\geqq 65$ & & $56(23.1 \%)$ & $3(5.5 \%)$ & $13(14.9 \%)$ & 40 (44.9\%) & \\
\hline Gender & & & & & & 0.331 \\
\hline Female & & 87 (36.0\%) & 19 (28.8\%) & 35 (40.2\%) & 33 (37.1\%) & \\
\hline Male & & $155(64.0 \%)$ & 47 (71.2\%) & $52(59.8 \%)$ & $56(62.9 \%)$ & \\
\hline Grade of differentiation & & & & & & 0.214 \\
\hline Well or moderately & & $120(49.6 \%)$ & 27 (40.9\%) & 44 (50.6\%) & $49(55.1 \%)$ & \\
\hline Poorly & & $122(50.4 \%)$ & $39(59.1 \%)$ & $43(49.4 \%)$ & $40(44.9 \%)$ & \\
\hline Primary tumor site & & & & & & 0.259 \\
\hline $\begin{array}{l}\text { Left (splenic flexure, descending colon, and } \\
\text { sigmoid colon) }\end{array}$ & & $94(38.8 \%)$ & $21(31.8 \%)$ & $39(44.8 \%)$ & $34(38.2 \%)$ & \\
\hline $\begin{array}{l}\text { Right (cecum, ascending colon, hepatic flexure, } \\
\text { and transverse colon) }\end{array}$ & & $148(61.2 \%)$ & $45(68.2 \%)$ & $48(55.2 \%)$ & $55(61.8 \%)$ & \\
\hline Initial bowel obstruction & & & & & & 0.028 \\
\hline No & & $153(63.2 \%)$ & $48(72.7 \%)$ & $58(66.7 \%)$ & 47 (52.8\%) & \\
\hline Yes & & 89 (36.8\%) & $18(27.3 \%)$ & 29 (33.3\%) & $42(47.2 \%)$ & \\
\hline Vascular invasion and/or lymphatic infiltration & & & & & & 0.282 \\
\hline No & & $186(76.9 \%)$ & 55 (83.3\%) & $63(72.4 \%)$ & $68(76.4 \%)$ & \\
\hline Yes & & $56(23.1 \%)$ & $11(16.7 \%)$ & $24(27.6 \%)$ & $21(23.6 \%)$ & \\
\hline Perineural invasion & & & & & & 0.621 \\
\hline No & & 220 (90.9\%) & $61(92.4 \%)$ & 77 (88.5\%) & $82(92.1 \%)$ & \\
\hline Yes & & $22(9.1 \%)$ & $5(7.6 \%)$ & $10(11.5 \%)$ & 7 (7.9\%) & \\
\hline No. of lymph nodes excised & & & & & & 0.503 \\
\hline$<12$ & & $19(7.9 \%)$ & $3(4.5 \%)$ & $8(9.2 \%)$ & $8(9.0 \%)$ & \\
\hline$\geqq 12$ & & $223(92.1 \%)$ & $63(95.5 \%)$ & $79(90.8 \%)$ & $81(91.0 \%)$ & \\
\hline Pathologic T stage & & & & & & 0.411 \\
\hline T1-T3 & & $193(79.8 \%)$ & $51(77.3 \%)$ & 67 (77.0\%) & 75 (84.3\%) & \\
\hline T4 & & 49 (20.2\%) & $15(22.7 \%)$ & $20(23.0 \%)$ & $14(15.7 \%)$ & \\
\hline Pathologic N stage & & & & & & 0.002 \\
\hline NO & & 105 (43.4\%) & 17 (25.8\%) & 37 (42.5\%) & $51(57.3 \%)$ & \\
\hline N1 & & $104(43.0 \%)$ & 35 (53.0\%) & 37 (42.5\%) & 32 (36.0\%) & \\
\hline N2 & & $33(13.6 \%)$ & $14(21.2 \%)$ & $13(14.9 \%)$ & $6(6.7 \%)$ & \\
\hline Pathologic TNM stage & & & & & & $<0.001$ \\
\hline High-risk stage II & & 105 (43.4\%) & $17(25.8 \%)$ & 37 (42.5\%) & 51 (57.3\%) & \\
\hline Stage III & & $137(56.6 \%)$ & $49(74.2 \%)$ & $50(57.5 \%)$ & $38(42.7 \%)$ & \\
\hline KRAS mutation & & & & & & 0.602 \\
\hline No & & $109(61.2 \%)$ & 30 (57.7\%) & $43(59.7 \%)$ & $36(66.7 \%)$ & \\
\hline Yes & & 69 (38.8\%) & 22 (42.3\%) & $29(40.3 \%)$ & $18(33.3 \%)$ & \\
\hline Missing values & 64 & & & & & \\
\hline \multicolumn{7}{|l|}{ NRAS mutation } \\
\hline No & & 174 (98.9\%) & $51(100 \%)$ & $71(100 \%)$ & 52 (96.3\%) & 0.102 \\
\hline Yes & & $2(1.1 \%)$ & 0 & 0 & 2 (3.7\%) & \\
\hline Missing values & 64 & & & & & \\
\hline BRAF mutation & & & & & & 0.073 \\
\hline No & & $161(90.4 \%)$ & 50 (96.2\%) & 66 (91.7\%) & 45 (83.3\%) & \\
\hline Yes & & $17(9.6 \%)$ & $2(3.8 \%)$ & $6(8.3 \%)$ & $9(16.7 \%)$ & \\
\hline Missing values & 66 & & & & & \\
\hline PIK3CA mutation & & & & & & 0.765 \\
\hline No & & 148 (84.1\%) & 44 (86.3\%) & 58 (81.7\%) & 46 (85.2\%) & \\
\hline Yes & & 28 (15.9\%) & 7 (13.7\%) & 13 (18.3\%) & $8(14.8 \%)$ & \\
\hline Missing values & 66 & & & & & \\
\hline
\end{tabular}

Some previous data suggested that the effect of 5-FU chemotherapy was dependent on the MMR status, and that dMMR CC patients might not benefit from 5-FU monotherapy compared to patients with pMMR CC $(11,19,23,29)$. A possible biological explanation is that in the absence of a functional MMR system, repair may only occur through the "base excision repair" system, a process that is less affected by the dNTP disequilibrium induced by $5-\mathrm{FU}(30)$. However, prolonged treatment with $5-\mathrm{FU}$ 

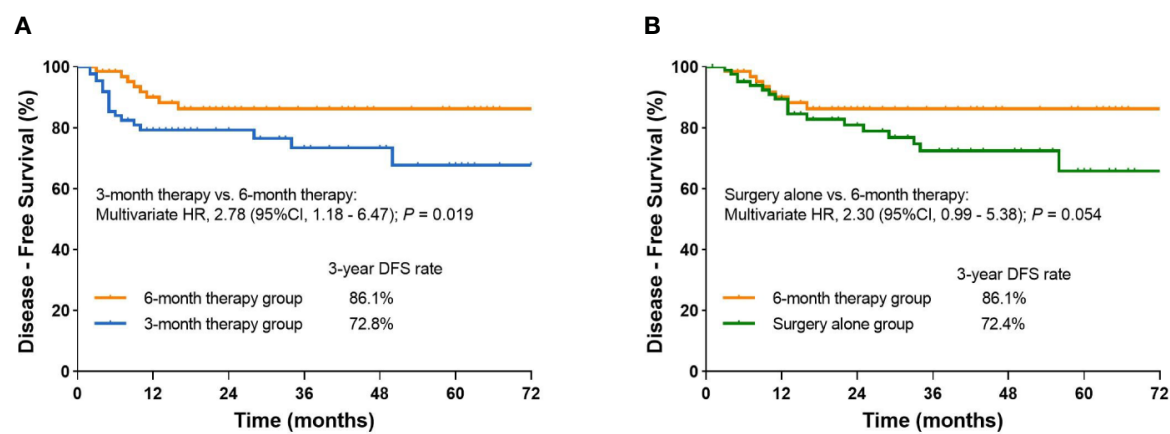

FIGURE 2 | (A) Kaplan-Meier curve of disease-free survival comparing 6-month therapy group and 3-month therapy group; (B) Kaplan-Meier curve of disease-free survival comparing 6-month therapy group and surgery alone group.

leads to the accumulation of DNA lesions that are targeted by another repair pathway (31), and oxaliplatin forms DNA adducts that result in the distortion of secondary DNA structure that is poorly recognized by MMR complexes $(32,33)$. These might explain why 6-month FOLFOX adjuvant therapy was superior to 3 -month therapy in this present study.

Perineural invasion, less than 12 lymph nodes excised, and T4 are independently associated with the decreased DFS in the present analyses. There was no significant difference in DFS among different therapy duration groups in these subgroups of patients, which might be due to the limited number of the cases (data are not shown). These assessments of high-risk factors in daily practice should be discussed because they provide potentially important prognostic information for dMMR CC patients and will help to tailor adjuvant therapy.

Molecular testing (RAS, BRAF) is currently a routine part of clinical practice in colorectal cancer. However, for stage II and III CC patients, the prognostic role of these markers is controversial,
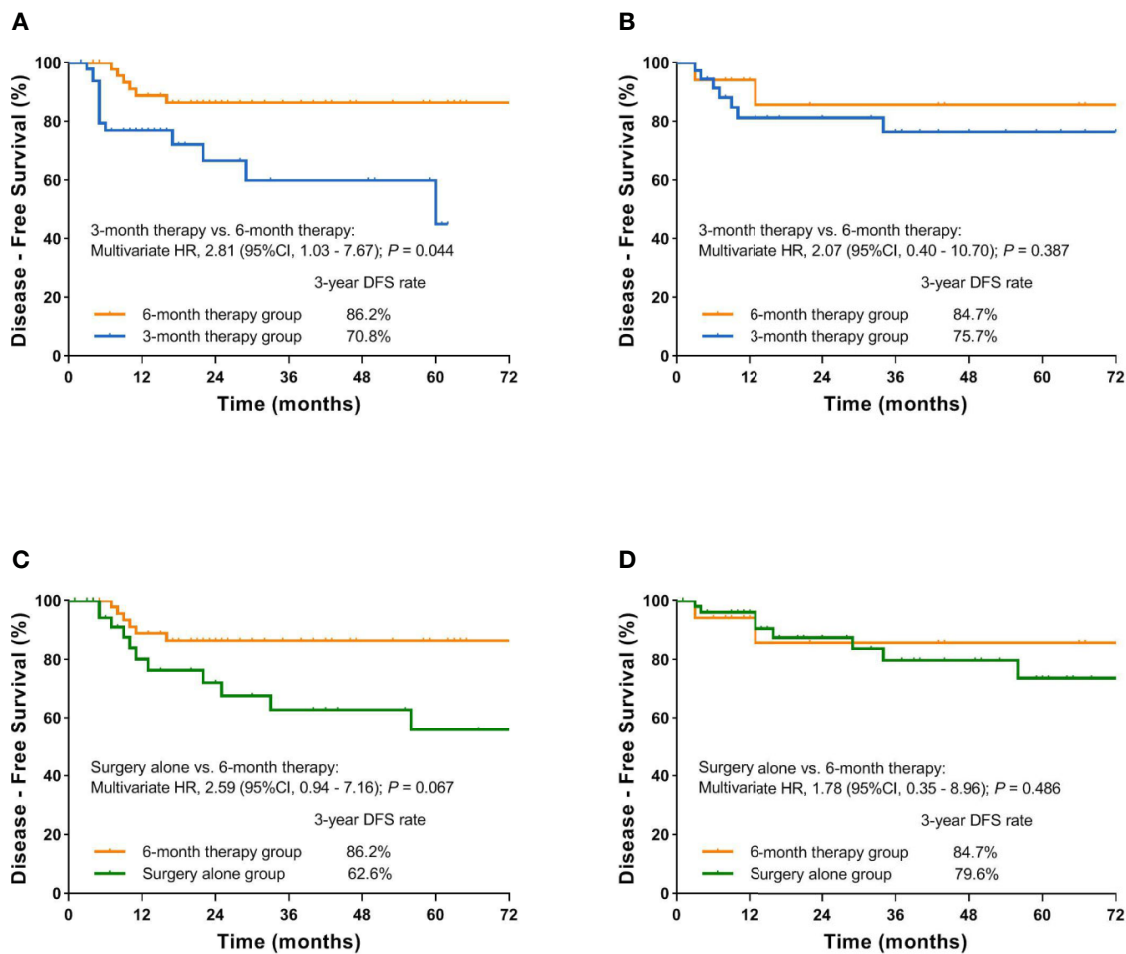

FIGURE 3 | (A) Kaplan-Meier curve of disease-free survival comparing 6-month therapy group and 3-month therapy group for patients with pathologic stage III; (B) Kaplan-Meier curve of disease-free survival comparing 6-month therapy group and 3-month therapy group for patients with high-risk stage II; (C) Kaplan-Meier curve of disease-free survival comparing 6-month therapy group and surgery alone group for patients with pathologic stage III; (D) Kaplan-Meier curve of diseasefree survival comparing 6-month therapy group and surgery alone group for patients with high-risk stage II. 
TABLE 2 | Univariate and multivariate Cox proportional hazards regression model for disease-free survival.

\begin{tabular}{|c|c|c|c|c|c|c|}
\hline \multirow[t]{2}{*}{ Variable } & \multirow[t]{2}{*}{ No. patients } & \multirow[t]{2}{*}{ No. events } & \multicolumn{2}{|c|}{ Univariate analysis } & \multicolumn{2}{|c|}{ Multivariate analysis } \\
\hline & & & HR (95\% Cl) & $\boldsymbol{P}$ & HR (95\% Cl) & $\boldsymbol{P}$ \\
\hline Total & 242 & 46 & & & & \\
\hline \multicolumn{7}{|l|}{ Age } \\
\hline$<65$ years & 186 & 33 & 1 & 0.360 & & \\
\hline$\geqq 65$ years & 56 & 13 & $1.35(0.71-2.56)$ & & & \\
\hline \multicolumn{7}{|l|}{ Gender } \\
\hline Female & 87 & 16 & 1 & 0.900 & & \\
\hline Male & 155 & 30 & $0.96(0.52-1.76)$ & & & \\
\hline \multicolumn{7}{|l|}{ Grade of differentiation } \\
\hline Well or moderately & 120 & 23 & 1 & 0.970 & & \\
\hline Poorly & 122 & 23 & $1.01(0.57-1.80)$ & & & \\
\hline \multicolumn{7}{|l|}{ Primary tumor site } \\
\hline Left & 94 & 23 & 1 & 0.170 & & \\
\hline Right & 148 & 23 & 0.67 (0.37-1.19) & & & \\
\hline \multicolumn{7}{|l|}{ Initial bowel obstruction } \\
\hline No & 153 & 29 & 1 & 0.580 & & \\
\hline Yes & 89 & 17 & $0.84(0.46-1.54)$ & & & \\
\hline \multicolumn{7}{|c|}{ Vascular invasion and/or lymphatic infiltration } \\
\hline No & 186 & 31 & 1 & 0.014 & 1 & 0.059 \\
\hline Yes & 56 & 15 & $2.16(1.17-4.01)$ & & 1.89 (0.98-3.68) & \\
\hline \multicolumn{7}{|l|}{ Perineural invasion } \\
\hline No & 220 & 37 & 1 & 0.001 & 1 & 0.004 \\
\hline Yes & 22 & 9 & $3.37(1.62-6.99)$ & & $3.26(1.47-7.24)$ & \\
\hline \multicolumn{7}{|l|}{ No. of lymph nodes excised } \\
\hline$\geqq 12$ & 223 & 38 & 1 & 0.002 & 1 & $<0.001$ \\
\hline$<12$ & 19 & 8 & $3.33(1.55-7.14)$ & & $5.09(2.23-11.62)$ & \\
\hline \multicolumn{7}{|l|}{ Pathologic T stage } \\
\hline T1-T3 & 193 & 29 & 1 & $<0.001$ & 1 & $<0.001$ \\
\hline T4 & 49 & 17 & $3.07(1.68-5.61)$ & & 3.39 (1.83-6.30) & \\
\hline \multicolumn{7}{|l|}{ Pathologic N stage } \\
\hline NO & 105 & 17 & 1 & 0.220 & 1 & 0.081 \\
\hline N1-2 & 137 & 29 & $1.45(0.80-2.64)$ & & $1.80(0.93-3.47)$ & \\
\hline \multicolumn{7}{|l|}{ KRAS mutation } \\
\hline No & 109 & 15 & 1 & 0.278 & & \\
\hline Yes & 69 & 12 & $1.53(0.71-3.27)$ & & & \\
\hline \multicolumn{7}{|l|}{ BRAF mutation } \\
\hline No & 161 & 25 & 1 & 0.971 & & \\
\hline Yes & 17 & 2 & $0.97(0.23-4.12)$ & & & \\
\hline \multicolumn{7}{|l|}{ PIK3CA mutation } \\
\hline No & 148 & 22 & 1 & 0.315 & & \\
\hline Yes & 28 & 5 & $1.65(0.62-4.38)$ & & & \\
\hline \multicolumn{7}{|c|}{ Adjuvant chemotherapy duration } \\
\hline 6-month therapy group & 66 & 8 & 1 & & 1 & \\
\hline 3-month therapy group & 87 & 19 & $2.43(1.06-5.55)$ & 0.036 & $2.78(1.18-6.47)$ & 0.019 \\
\hline Surgery alone group & 89 & 19 & $1.95(0.85-4.46)$ & 0.113 & 2.30 (0.99-5.38) & 0.054 \\
\hline
\end{tabular}

$\mathrm{Cl}$, confidence interval; HR, hazard ratio.

particularly among dMMR patients. In a pooled analysis of PETACC-8 and N0147, and a post hoc analysis of the PETACC-8, both included resected stage III colon cancer patients receiving adjuvant FOLFOX, BRAF or KRAS mutations are independently associated with the decreased DFS in patients with pMMR, but not dMMR tumors $(34,35)$. These findings could explain why there was no difference of DFS in patients with KRAS, BRAF, or PIK3CA mutation tumors as compared with wild-type patients in our study.

There were some limitations of our study. First, this was a singlecenter retrospective study that caused the imbalances in baseline characteristics among the three groups. Fewer patients in the 3month therapy group and the surgery alone group were in stage III than those in the 6-month therapy group. Propensity score matching was conducted to mitigate the potential bias caused by confounding covariates. The differences in DFS between the 6month therapy group and the 3-month therapy group were consistent and robust before and after matching. Nevertheless, high-quality randomized controlled clinical trials or subgroup analyses based on a large sample size from IDEA collaboration study are demanded to confirm the optimal duration of chemotherapy for patients with stage III dMMR CC. Second, the duration of adjuvant therapy was left to investigators' discretion in this observation, which was mainly based on not just the disease characteristics but also patient's age and preference. Before matching, the median age of patients in the surgery alone group was significantly older than that of patients in the 3-month therapy group and the 6-month therapy group, that is, 63,50 , and 49 years 
TABLE 3 | Selected baseline characteristics before and after propensity score matching.

\begin{tabular}{|c|c|c|c|c|c|c|c|c|}
\hline \multirow[t]{3}{*}{ Characteristics } & \multicolumn{4}{|c|}{ No. (\%) } & \multicolumn{4}{|c|}{ No. (\%) } \\
\hline & \multicolumn{4}{|c|}{ Before matching } & \multicolumn{4}{|c|}{ After matching } \\
\hline & $\begin{array}{l}\text { 6-month therapy } \\
\text { group, } n=66\end{array}$ & $\begin{array}{l}\text { 3-month therapy } \\
\text { group, } \mathrm{n}=87\end{array}$ & $P$ & $\begin{array}{l}\text { Standardized } \\
\text { difference }\end{array}$ & $\begin{array}{l}\text { 6-month therapy } \\
\text { group, } n=51\end{array}$ & $\begin{array}{l}\text { 3-month therapy } \\
\text { group, } n=51\end{array}$ & $P$ & $\begin{array}{l}\text { Standardized } \\
\text { difference }\end{array}$ \\
\hline \multicolumn{9}{|l|}{ Age, years } \\
\hline Median (range) & $49(22-78)$ & $50(23-77)$ & 0.337 & 0.190 & $50(22-78)$ & $48(26-76)$ & 0.269 & 0.030 \\
\hline$<65$ & $63(95.5 \%)$ & $74(85.1 \%)$ & & & 49 (96.1\%) & $45(88.2 \%)$ & & \\
\hline$\geqq 65$ & 3 (5.5\%) & $13(14.9 \%)$ & & & 2 (3.9\%) & $6(11.8 \%)$ & & \\
\hline Pathologic T stage & & & 1.000 & 0.006 & & & 1.000 & $<0.001$ \\
\hline $\mathrm{T} 1-3$ & $51(77.3 \%)$ & 67 (77.0\%) & & & $38(74.5 \%)$ & 38 (74.5\%) & & \\
\hline $\mathrm{T} 4$ & $15(22.7 \%)$ & $20(23.0 \%)$ & & & $13(25.5 \%)$ & $13(25.5 \%)$ & & \\
\hline Pathologic N stage & & & 0.040 & 0.357 & & & 1.000 & 0.042 \\
\hline No & $17(25.8 \%)$ & $37(42.5 \%)$ & & & $16(31.4 \%)$ & $15(29.4 \%)$ & & \\
\hline $\mathrm{N} 1-2$ & $49(74.2 \%)$ & $50(57.5 \%)$ & & & 35 (68.6\%) & $36(70.6 \%)$ & & \\
\hline Initial bowel obstruction & & & 0.481 & 0.131 & & & 1.000 & 0.042 \\
\hline No & 48 (72.7\%) & $58(66.7 \%)$ & & & 36 (70.6\%) & 35 (68.6\%) & & \\
\hline Yes & $18(27.3 \%)$ & 29 (33.3\%) & & & $15(29.4 \%)$ & $16(31.4 \%)$ & & \\
\hline $\begin{array}{l}\text { Vascular invasion and/or } \\
\text { lymphatic infiltration }\end{array}$ & & & 0.124 & 0.264 & & & 1.000 & 0.046 \\
\hline No & 55 (83.3\%) & $63(72.4 \%)$ & & & $40(78.4 \%)$ & 39 (76.5\%) & & \\
\hline Yes & $11(16.7 \%)$ & $24(27.6 \%)$ & & & $11(21.6 \%)$ & $12(23.5 \%)$ & & \\
\hline Perineural invasion & & & 0.585 & 0.133 & & & 1.000 & 0.068 \\
\hline No & $61(92.4 \%)$ & 77 (88.5\%) & & & 47 (92.2\%) & 46 (90.2\%) & & \\
\hline Yes & $5(7.6 \%)$ & $10(11.5 \%)$ & & & $4(7.8 \%)$ & $5(9.8 \%)$ & & \\
\hline \multirow[t]{3}{*}{ Characteristics } & \multicolumn{4}{|c|}{ No. (\%) } & \multicolumn{4}{|c|}{ No. $(\%)$} \\
\hline & \multicolumn{4}{|c|}{ Before matching } & \multicolumn{4}{|c|}{ After matching } \\
\hline & $\begin{array}{c}\text { 6-month therapy } \\
\text { group, } n=66\end{array}$ & $\begin{array}{c}\text { Surgery alone } \\
\text { group, } n=89\end{array}$ & $\boldsymbol{P}$ & $\begin{array}{c}\text { Standardized } \\
\text { difference }\end{array}$ & $\begin{array}{c}\text { 6-month therapy } \\
\text { group, } n=35\end{array}$ & $\begin{array}{c}\text { Surgery alone } \\
\text { group, } n=35\end{array}$ & $\boldsymbol{P}$ & $\begin{array}{c}\text { Standardized } \\
\text { difference }\end{array}$ \\
\hline \multicolumn{9}{|l|}{ Age, years } \\
\hline Median (range) & $49(22-78)$ & $63(22-88)$ & $<0.001$ & 1.053 & $49(22-78)$ & $56(23-76)$ & 1.000 & $<0.001$ \\
\hline$<65$ & $63(95.5 \%)$ & $49(55.1 \%)$ & & & $32(91.4 \%)$ & $32(91.4 \%)$ & & \\
\hline$\geqq 65$ & $3(5.5 \%)$ & $40(44.9 \%)$ & & & $3(8.6 \%)$ & $3(8.6 \%)$ & & \\
\hline Pathologic T stage & & & 0.302 & 0.177 & & & 1.000 & $<0.001$ \\
\hline $\mathrm{T} 1-3$ & $51(77.3 \%)$ & 75 (84.3\%) & & & 27 (77.1\%) & 27 (77.1\%) & & \\
\hline $\mathrm{T} 4$ & $15(22.7 \%)$ & $14(15.7 \%)$ & & & $8(22.9 \%)$ & $8(22.9 \%)$ & & \\
\hline Pathologic N stage & & & $<0.001$ & 0.671 & & & 1.000 & $<0.001$ \\
\hline NO & $17(25.8 \%)$ & $51(57.3 \%)$ & & & $14(40.0 \%)$ & $14(40.0 \%)$ & & \\
\hline $\mathrm{N} 1-2$ & 49 (74.2\%) & $38(42.7 \%)$ & & & 21 (60.0\%) & $21(60.0 \%)$ & & \\
\hline Initial bowel obstruction & & & 0.013 & 0.418 & & & 1.000 & 0.063 \\
\hline No & 48 (72.7\%) & 47 (52.8\%) & & & 25 (71.4\%) & $26(74.3 \%)$ & & \\
\hline Yes & $18(27.3 \%)$ & $42(47.2 \%)$ & & & $10(28.6 \%)$ & $9(25.7 \%)$ & & \\
\hline $\begin{array}{l}\text { Vascular invasion and/or } \\
\text { lymphatic infiltration }\end{array}$ & & & 0.322 & 0.172 & & & 1.000 & 0.094 \\
\hline No & $55(83.3 \%)$ & $68(76.4 \%)$ & & & $32(91.4 \%)$ & $31(88.6 \%)$ & & \\
\hline Yes & $11(16.7 \%)$ & $21(23.6 \%)$ & & & $3(8.6 \%)$ & $4(11.4 \%)$ & & \\
\hline Perineural invasion & & & 1.000 & 0.011 & & & 1.000 & $<0.001$ \\
\hline No & $61(92.4 \%)$ & 82 (92.1\%) & & & 32 (91.4\%) & 32 (91.4\%) & & \\
\hline Yes & 5 (7.6\%) & 7 (7.9\%) & & & 3 (8.6\%) & 3 (8.6\%) & & \\
\hline
\end{tabular}

old respectively. MOSAIC and NSABP C-07 study revealed no statistically significant survival benefit for the addition of oxaliplatin to fluorouracil with leucovorin as adjuvant treatment for patients older than $70(36,37)$. In addition, patients with dMMR tumors may not benefit from adjuvant chemotherapy with 5-FU alone. For stage III patients in the surgery alone group, $26.3 \%$ of them were older than 70 . These may be a potential reason why 38 stage III patients did not receive any adjuvant chemotherapy. Third, dMMR in colon cancer is most commonly caused by epigenetic inactivation of MLH1 by promoter hypermethylation in a setting of CpG island methylator phenotype (CIMP) in sporadic tumors (approximately $75 \%)(38,39)$, and the remainder of dMMR tumors are associated with germline mutations (40). A study based on a large database from randomized trials in colon cancer stage III patients suggested that the dMMR tumors with suspected germline mutations were associated with improved DFS after 5-FU-based adjuvant treatment compared with sporadic tumors where no benefit was observed (24). The absence of the family history information and methylation status of MLH1 of our cohort made it difficult to analyze the mechanism of MMR deficiency. 
A

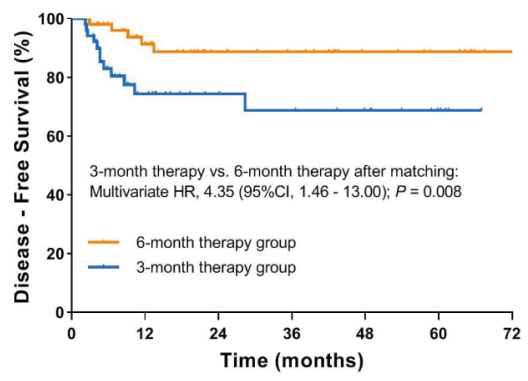

C

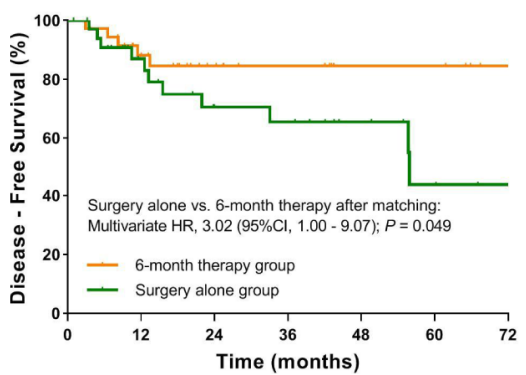

B

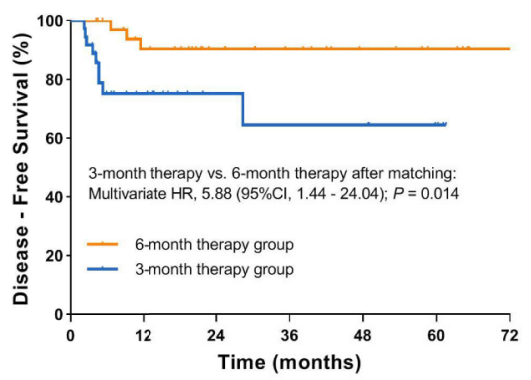

D

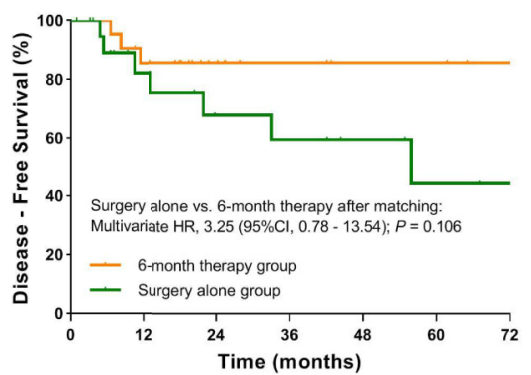

FIGURE 4 | (A) Kaplan-Meier curve of disease-free survival comparing 3-month therapy group and 6-month therapy group after propensity score matching; (B) Kaplan-Meier curve of disease-free survival comparing 3-month therapy group and 6-month therapy group for patients with stage III after propensity score matching; (C) Kaplan-Meier curve of disease-free survival comparing surgery alone group and 6-month therapy group after propensity score matching; (D) KaplanMeier curve of disease-free survival comparing surgery alone and 6-month therapy group for patients with stage III after propensity score matching.

In conclusion, this study suggests that 6-month duration of mFOLFOX6 adjuvant chemotherapy in dMMR CC patients may be associated with improved DFS compared with 3-month therapy, particularly in stage III patients. However, these results are limited by the presence of potential unmeasured confounding in this retrospective study and require further investigations for confirmation.

\section{DATA AVAILABILITY STATEMENT}

The original contributions presented in the study are included in the article/Supplementary Material. Further inquiries can be directed to the corresponding authors.

\section{ETHICS STATEMENT}

This study was approved by the Institutional Review Boards of The Sixth Affiliated Hospital of Sun Yat-Sen University. Written informed consent for participation was not required for this study in accordance with the national legislation and the institutional requirements.

\section{AUTHOR CONTRIBUTIONS}

$\mathrm{HH}, \mathrm{ZW}$, and $\mathrm{YH}$ carried out the studies, participated in collecting data, and drafted the manuscript. CW, JZ, YC, JXL, XYX, CS, WL, and JYL performed the statistical analysis and participated in its design. XHX and YD participated in acquisition, analysis, or interpretation of data and drafted the manuscript. All authors contributed to the article and approved the submitted version.

\section{FUNDING}

This work was supported by Science and Technology Planning Project of Guangzhou (Grant No. 201904010394) and Science and Technology Program of Guangzhou (Grant No. 201803010073).

\section{SUPPLEMENTARY MATERIAL}

The Supplementary Material for this article can be found online at: https://www.frontiersin.org/articles/10.3389/fonc.2020. 579478/full\#supplementary-material 


\section{REFERENCES}

1. Bray F, Ferlay J, Soerjomataram I, Siegel RL, Torre LA, Jemal A. Global cancer statistics 2018: GLOBOCAN estimates of incidence and mortality worldwide for 36 cancers in 185 countries. CA Cancer J Clin (2018) 68:394-424. doi: 10.3322/ caac. 21492

2. Andre T, Boni C, Mounedji-Boudiaf L, Navarro M, Tabernero J, Hickish T, et al. Oxaliplatin, fluorouracil, and leucovorin as adjuvant treatment for colon cancer. N Engl J Med (2004) 350:2343-51. doi: 10.1056/NEJMoa032709

3. André T, Boni C, Navarro M, Tabernero J, Hickish T, Topham C, et al. Improved Overall Survival With Oxaliplatin, Fluorouracil, and Leucovorin As Adjuvant Treatment in Stage II or III Colon Cancer in the MOSAIC Trial. J Clin Oncol (2009) 27:3109-16. doi: 10.1200/JCO.2008.20.6771

4. Haller DG, Tabernero J, Maroun J, de Braud F, Price T, Van Cutsem E, et al. Capecitabine plus oxaliplatin compared with fluorouracil and folinic acid as adjuvant therapy for stage III colon cancer. J Clin Oncol (2011) 29:1465-71. doi: 10.1200/JCO.2010.33.6297

5. Kuebler JP, Wieand HS, O'Connell MJ, Smith RE, Colangelo LH, Yothers G, et al. Oxaliplatin Combined With Weekly Bolus Fluorouracil and Leucovorin As Surgical Adjuvant Chemotherapy for Stage II and III Colon Cancer: Results From NSABP C-07. J Clin Oncol (2007) 25:2198-204. doi: 10.1200/ JCO.2006.08.2974

6. André T, de Gramont A, Vernerey D, Chibaudel B, Bonnetain F, TijerasRaballand A, et al. Adjuvant Fluorouracil, Leucovorin, and Oxaliplatin in Stage II to III Colon Cancer: Updated 10-Year Survival and Outcomes According to BRAF Mutation and Mismatch Repair Status of the MOSAIC Study. J Clin Oncol (2015) 33:4176-87. doi: 10.1200/JCO.2015.63.4238

7. Grothey A. Oxaliplatin-safety profile: neurotoxicity. Semin Oncol (2003) 30:5. doi: 10.1053/S0093-7754(03)00399-3

8. Grothey A, Sobrero AF, Shields AF, Yoshino T, Paul J, Taieb J, et al. Duration of Adjuvant Chemotherapy for Stage III Colon Cancer. N Engl J Med (2018) 378:1177-88. doi: 10.1056/NEJMoa1713709

9. Andre T, Vernerey D, Mineur L, Bennouna J, Desrame J, Faroux R, et al. Three Versus 6 Months of Oxaliplatin-Based Adjuvant Chemotherapy for Patients With Stage III Colon Cancer: Disease-Free Survival Results From a Randomized, Open-Label, International Duration Evaluation of Adjuvant (IDEA) France, Phase III Trial. J Clin Oncol (2018) 36:1469-77. doi: 10.1200/JCO.2017.76.0355

10. Ionov Y, Peinado MA, Malkhosyan S, Shibata D, Perucho M. Ubiquitous somatic mutations in simple repeated sequences reveal a new mechanism for colonic carcinogenesis. Nature (1993) 363:558-61. doi: 10.1038/363558a0

11. Ribic CM, Sargent DJ, Moore MJ, Thibodeau SN, French AJ, Goldberg RM, et al. Tumor microsatellite-instability status as a predictor of benefit from fluorouracil-based adjuvant chemotherapy for colon cancer. $N$ Engl J Med (2003) 349:247-57. doi: 10.1056/NEJMoa022289

12. Deng Z, Qin Y, Wang J, Wang G, Lang X, Jiang J, et al. Prognostic and predictive role of DNA mismatch repair status in stage II-III colorectal cancer: A systematic review and meta-analysis. Clin Genet (2019) 97:25-38. doi: 10.1111/cge.13628

13. Korphaisarn K, Pongpaibul A, Limwongse C, Roothumnong E, Klaisuban W, Nimmannit A, et al. Deficient DNA mismatch repair is associated with favorable prognosis in Thai patients with sporadic colorectal cancer. World J Gastroentero (2015) 21:926. doi: 10.3748/wjg.v21.i3.926

14. Zaanan A, Shi Q, Taieb J, Alberts SR, Meyers JP, Smyrk TC, et al. Role of Deficient DNA Mismatch Repair Status in Patients With Stage III Colon Cancer Treated With FOLFOX Adjuvant Chemotherapy. JAMA Oncol (2018) 4:379. doi: 10.1001/jamaoncol.2017.2899

15. Compton CC, Fielding LP, Burgart LJ, Conley B, Cooper HS, Hamilton SR, et al. Prognostic factors in colorectal cancer. College of American Pathologists Consensus Statement 1999. Arch Pathol Lab Med (2000) 124:979-94. doi: 10.1043/0003-9985(2000)124<0979:PFICC >2.0.CO;2

16. Luchini C, Bibeau F, Ligtenberg MJL, Singh N, Nottegar A, Bosse T, et al. ESMO recommendations on microsatellite instability testing for immunotherapy in cancer, and its relationship with PD-1/PD-L1 expression and tumour mutational burden: a systematic review-based approach. Ann Oncol (2019) 30:1232-43. doi: 10.1093/annonc/mdz116

17. Baudrin LG, Deleuze J, How-Kit A. Molecular and Computational Methods for the Detection of Microsatellite Instability in Cancer. Front Oncol (2018) 8:621. doi: $10.3389 /$ fonc. 2018.00621
18. Austin PC. Balance diagnostics for comparing the distribution of baseline covariates between treatment groups in propensity-score matched samples. Stat Med (2009) 28:3083-107. doi: 10.1002/sim.3697

19. Sargent DJ, Marsoni S, Monges G, Thibodeau SN, Labianca R, Hamilton SR, et al. Defective Mismatch Repair As a Predictive Marker for Lack of Efficacy of Fluorouracil-Based Adjuvant Therapy in Colon Cancer. J Clin Oncol (2010) 28:3219-26. doi: 10.1200/JCO.2009.27.1825

20. Gkekas I, Novotny J, Fabian P, Nemecek R, Palmqvist R, Strigård K, et al. Mismatch repair status predicts survival after adjuvant treatment in stage II colon cancer patients. J Surg Oncol (2019) 121:392-401. doi: 10.1002/ jso. 25798

21. Bertagnolli MM, Redston M, Compton CC, Niedzwiecki D, Mayer RJ, Goldberg RM, et al. Microsatellite instability and loss of heterozygosity at chromosomal location 18q: prospective evaluation of biomarkers for stages II and III colon cancer-a study of CALGB 9581 and 89803. J Clin Oncol (2011) 29:3153-62. doi: 10.1200/JCO.2010.33.0092

22. Hutchins G, Southward K, Handley K, Magill L, Beaumont C, Stahlschmidt J, et al. Value of mismatch repair, KRAS, and BRAF mutations in predicting recurrence and benefits from chemotherapy in colorectal cancer. J Clin Oncol (2011) 29:1261-70. doi: 10.1200/JCO.2010.30.1366

23. Jover R, Zapater P, Castells A, Llor X, Andreu M, Cubiella J, et al. Mismatch repair status in the prediction of benefit from adjuvant fluorouracil chemotherapy in colorectal cancer. GUT (2006) 55:848-55. doi: 10.1136/ gut.2005.073015

24. Sinicrope FA, Foster NR, Thibodeau SN, Marsoni S, Monges G, Labianca R, et al. DNA mismatch repair status and colon cancer recurrence and survival in clinical trials of 5-fluorouracil-based adjuvant therapy. J Natl Cancer Inst (2011) 103:863-75. doi: 10.1093/jnci/djr153

25. Argilés G, Tabernero J, Labianca R, Hochhauser D, Salazar R, Iveson T, et al. ESMO Guidelines Committee. Localised colon cancer: ESMO Clinical Practice Guidelines for diagnosis, treatment and follow-up. Ann Oncol (2020) 31(10):1291-305. doi: 10.1016/j.annonc.2020.06.022

26. Tougeron D, Mouillet G, Trouilloud I, Lecomte T, Coriat R, Aparicio T, et al. Efficacy of Adjuvant Chemotherapy in Colon Cancer With Microsatellite Instability: A Large Multicenter AGEO Study. J Natl Cancer Inst (2016) 108 (7). doi: $10.1093 /$ jnci/djv438

27. Alwers E, Jansen L, Blaker H, Kloor M, Tagscherer KE, Roth W, et al. Microsatellite instability and survival after adjuvant chemotherapy among stage II and III colon cancer patients: results from a population-based study. Mol Oncol (2020) 14:363-72. doi: 10.1002/1878-0261.12611

28. Sinicrope FA, Mahoney MR, Smyrk TC, Thibodeau SN, Warren RS, Bertagnolli MM, et al. Prognostic impact of deficient DNA mismatch repair in patients with stage III colon cancer from a randomized trial of FOLFOXbased adjuvant chemotherapy. J Clin Oncol (2013) 31:3664-72. doi: 10.1200/ JCO.2013.48.9591

29. Li LS, Morales JC, Veigl M, Sedwick D, Greer S, Meyers M, et al. DNA mismatch repair (MMR)-dependent 5-fluorouracil cytotoxicity and the potential for new therapeutic targets. Br J Pharmacol (2009) 158:679-92. doi: 10.1111/j.1476-5381.2009.00423.x

30. Fischer F, Baerenfaller K, Jiricny J. 5-Fluorouracil is efficiently removed from DNA by the base excision and mismatch repair systems. Gastroenterology (2007) 133:1858-68. doi: 10.1053/j.gastro.2007.09.003

31. Liu A, Yoshioka K, Salerno V, Hsieh P. The mismatch repair-mediated cell cycle checkpoint response to fluorodeoxyuridine. J Cell Biochem (2008) 105:245-54. doi: 10.1002/jcb.21824

32. Zdraveski ZZ, Mello JA, Farinelli CK, Essigmann JM, Marinus MG. MutS preferentially recognizes cisplatin- over oxaliplatin-modified DNA. J Biol Chem (2002) 277:1255-60. doi: 10.1074/jbc.M105382200

33. Hochster HS, Sargent DJ. One good DNA-damage deserves another: Oxaliplatin in MSI-high colon cancer. J Natl Cancer Inst (2016) 108(7): djw011. doi: 10.1093/jnci/djw011

34. Taieb J, Le Malicot K, Shi Q, Penault-Llorca F, Bouche O, Tabernero J, et al. Prognostic Value of BRAF and KRAS Mutations in MSI and MSS Stage III Colon Cancer. J Natl Cancer Inst (2016) 109(5):djw272. doi: 10.1093/jnci/djw272

35. Taieb J, Zaanan A, Le Malicot K, Julie C, Blons H, Mineur L, et al. Prognostic Effect of BRAF and KRAS Mutations in Patients With Stage III Colon Cancer Treated With Leucovorin, Fluorouracil, and Oxaliplatin With or Without 
Cetuximab: A Post Hoc Analysis of the PETACC-8 Trial. JAMA Oncol (2016) 2:643-53. doi: 10.1001/jamaoncol.2015.5225

36. Yothers G, O’Connell MJ, Allegra CJ, Kuebler JP, Colangelo LH, Petrelli NJ, et al. Oxaliplatin as adjuvant therapy for colon cancer: updated results of NSABP C-07 trial, including survival and subset analyses. J Clin Oncol (2011) 29:3768-74. doi: 10.1200/JCO.2011.36.4539

37. Renfro LA, Sargent DJ. Findings from the Adjuvant Colon Cancer End Points (ACCENT) Collaborative Group: the power of pooled individual patient data from multiple clinical trials. Chin Clin Oncol (2016) 5:80. doi: 10.21037/cco.2016.12.02

38. Herman JG, Umar A, Polyak K, Graff JR, Ahuja N, Issa JP, et al. Incidence and functional consequences of hMLH1 promoter hypermethylation in colorectal carcinoma. Proc Natl Acad Sci USA (1998) 95:6870-75. doi: 10.1073/pnas. 95.12.6870

39. Toyota M, Ahuja N, Ohe-Toyota M, Herman JG, Baylin SB, Issa JP. CpG island methylator phenotype in colorectal cancer. Proc Natl Acad Sci USA (1999) 96:8681-6. doi: 10.1073/pnas.96.15.8681
40. Aaltonen LA, Salovaara R, Kristo P, Canzian F, Hemminki A, Peltomaki P, et al. Incidence of hereditary nonpolyposis colorectal cancer and the feasibility of molecular screening for the disease. $N$ Engl J Med (1998) 338:1481-7. doi: 10.1056/NEJM199805213382101

Conflict of Interest: The authors declare that the research was conducted in the absence of any commercial or financial relationships that could be construed as a potential conflict of interest.

Copyright (๑) $2020 \mathrm{Hu}$, Wu, Wang, Huang, Zhang, Cai, Xie, Li, Shen, Li, Ling, Xu and Deng. This is an open-access article distributed under the terms of the Creative Commons Attribution License (CC BY). The use, distribution or reproduction in other forums is permitted, provided the original author(s) and the copyright owner(s) are credited and that the original publication in this journal is cited, in accordance with accepted academic practice. No use, distribution or reproduction is permitted which does not comply with these terms. 